\title{
Molecular Characterization of Cryptosporidium Isolates from Calves in Ishikari District, Hokkaido, Japan
}

\author{
Fumi MURAKOSHI $^{1)}$, Yoriko TOZAWA ${ }^{2)}$, Atsuko INOMATA ${ }^{1)}$, Taisuke HORIMOTO ${ }^{1)}$, Yoshihiro WADA ${ }^{2)}$ and \\ Kentaro $\mathrm{KATO}^{1,3) *}$ \\ ${ }^{1)}$ Department of Veterinary Microbiology, Graduate School of Agricultural and Life Sciences, The University of Tokyo, 1-1-1 Yayoi, \\ Bunkyo-ku, Tokyo 113-8657, Japan \\ ${ }^{2)}$ Ishikari Livestock Hygiene Service Center, 3 Hitsujigaoka, Toyohira, Sapporo, Hokkaido 062-0045, Japan \\ 3) National Research Center for Protozoan Diseases, Obihiro University of Agriculture and Veterinary Medicine, Inada-cho, Obihiro, \\ Hokkaido 080-8555, Japan
}

(Received 28 September 2012/Accepted 31 January 2013/Published online in J-STAGE 14 February 2013)

ABSTRACT. Cattle are major hosts of Cryptosporidium. Cryptosporidiosis in neonatal calves is associated with retarded growth, weight loss and calf mortality, and zoonotic infections in humans. Fecal samples were collected from calves in Ishikari District, Hokkaido, Japan and examined by PCR and sequence analyses. Among the 107 fecal samples collected in May and June 2012, 25 (23\%) were positive for Cryptosporidium, including 8 samples (7\%) having C. parvum, 10 (9\%) having C. bovis and 7 (7\%) having C. ryanae. This is first time C. ryanae has been detected in Hokkaido. Furthermore, it is the first detection of C. ryanae from pre-weaned calves in Japan. Microscopic observation with the flotation method is powerful and traditional tool for screening for Cryptosporidium species, but it sometimes leads to low detection of Cryptosporidium with low oocyst shedding intensity. If calves with or without diarrhea are examined using the molecular diagnostic tools, C. bovis and C. ryanae might be detected in other areas of Japan including Hokkaido. Here, the zoonotic species, $C$. parvum, was also observed. Therefore, calves can be potential sources of cryptosporidial infections for humans and other animals. The detection of C. parvum was statistically correlated with diarrhea in calves.

KEY WORDS: cattle, Cryptosporidium bovis, Cryptosporidium parvum, Cryptosporidium ryanae, Hokkaido.

doi: 10.1292/jvms.12-0435; J. Vet. Med. Sci. 75(7): 837-840, 2013

Cattle are major hosts of Cryptosporidium spp. [23]. They are primarily infected with four Cryptosporidium species, namely Cryptosporidium parvum, Cryptosporidium bovis, Cryptosoridium ryanae and Cryptosporidium andersoni. $C$. parvum has been reported to be the zoonotic species and the major cause of diarrhea in calves [27, 32]. Oocyst shedding from cattle has been reported to be a contamination source in human cryptosporidiosis outbreaks [21]. Additionally, cryptosporidiosis is associated with neonatal diarrhea syndrome in calves, leading to direct and indirect economic losses [4]. Therefore, the studies on species distribution and transmission routes of Cryptosporidium spp. are important in public health and food production.

In Japan, there are very few studies on the epidemiology of Cryptosporidium in cattle. Additionally, most previous epidemiological studies of cryptosporidiosis in cattle were performed by only microscopic observations of oocyst shedding or microscopic observation used for initial screening of molecular epidemiology. However, these traditional screening methods might lead to low detection of Cryptosporidium species with low oocyst shedding intensity. There are dif-

\footnotetext{
*Correspondence to: Kato, K., Department of Veterinary Microbiology, Graduate School of Agricultural and Life Sciences, The University of Tokyo, 1-1-1 Yayoi, Bunkyo-ku, Tokyo 113-8657, Japan.

e-mail: akkato@mail.ecc.u-tokyo.ac.jp

(C)2013 The Japanese Society of Veterinary Science
}

fering results according to the type and age of host animals, area of study, detection methods and season, and because of this variation, more epidemiological studies are needed.

To assess the potential public health and production importance, Cryptosporidium infection in pre- and post-weaned calves in Ishikari District, Hokkaido, Japan was examined. Our study is an initial Cryptosporidium screening of Ishikari District. Specifically, we analyzed the relationships between the occurrence of diarrhea, genotype/subtype and age using molecular diagnostic tools.

\section{MATERIALS AND METHODS}

Collection of samples: Fecal samples were collected from 27 farms located in Ishikari District, Hokkaido, Japan. We collected samples from 86 dairy, 17 Japanese black and 4 crossbred calves (Bos taurus) that ranged in age from 2 to 120 days. A total of 107 samples were randomly collected at each farm (1-8 calves per farm) in May and June, 2012. Specimens were stored at $4{ }^{\circ} \mathrm{C}$ prior to DNA extraction and microscopic examination.

Sample analysis: DNA was extracted using easy beads (AMR, Gifu, Japan) and QIAamp® DNAstool minikit (Qiagen, Hilden, Germany). For DNA extraction, 0.3-0.4 g of fecal specimen was used. Cryptosporidium spp. were detected and subtyped by nested polymerase chain reaction (PCR) amplification targeting a $\sim 830 \mathrm{bp}$ and $\sim 850 \mathrm{bp}$ fragments of the small subunit (SSU) rRNA and $60 \mathrm{kDa}$ glycoprotein (GP60) genes, respectively, as described previously [8]. 
Table 1. Infection rates of Cryptosporidium in fecal samples from calves

\begin{tabular}{ccccc}
\hline & C. parvum & C. bovis & C. ryanae & sum \\
\hline pre weaned 1-8 weeks $(\mathrm{n}=79)$ & 8 & 5 & 4 & 17 \\
post weaned 3-12 months $(\mathrm{n}=28)$ & 0 & 5 & 3 & 8 \\
\hline \multicolumn{1}{c}{ sum } & 8 & 10 & 7 & 25 \\
\hline
\end{tabular}

Table 2. Correlation between diarrhea and detected genotype

\begin{tabular}{lcccc}
\hline & C. parvum & C. bovis & C. ryanae & ND \\
\hline diarrhea & 5 & 2 & 2 & 16 \\
normal & 3 & 8 & 5 & 64 \\
\hline
\end{tabular}

ND: not detected.

C. parvum was statistically correlated with diarrhea $(P<0.05)$.

GP60 gene was used to subtype C.parvum. For each sample, PCR detection was repeated independently at least two times. All secondary PCR products determined to be Cryptosporidium positive were sequenced in both directions using an ABI 3130 Genetic Analyzer (Applied Biosystems Japan, Tokyo, Japan) with the secondary primers and the BigDye Terminator v3.1 Cycle Sequencing Kit (Applied Biosystems Japan). The sequences obtained were aligned using ClustalX 2 [15], edited manually in BioEdit 7.0.5.3 [9] and compared to $C$. parvum, $C$. bovis and $C$. ryanae reference sequences in GenBank. Unique 18S rRNA and GP60 sequences acquired in this study were deposited in the GenBank database under accession numbers; AB746195-AB746198.

The sugar flotation method and microscopic examination were also performed for Cryptosporidium positive fecal samples as described elsewhere. In brief, $1 \mathrm{~g}$ of feces was suspended in sucrose $(1.2 \mathrm{~g} / \mathrm{m} l)$, and oocysts were floated to slide grass.

Statistical analyses: Data were compared using a Fisher's exact test with the use of R 2.13.0 software. Differences at $P<0.05$ were considered significant.

\section{RESULTS}

Genotype and analysis: Of the 107 fecal samples, 25 samples $(23 \%)$ were positive for Cryptosporidium infection based on PCR-sequence analysis. Three Cryptosporidium species (C. parvum, $C$. bovis and C. ryanae) were detected; $8(7 \%), 10(9 \%)$ and 7 (7\%) samples had C.parvum, C. bovis and $C$. ryanae, respectively. The percentage of each genotype of Cryptosporidium represented among the 25 Cryptosporidium positive specimens in the two age categories (preweaned; 1-8 weeks and post-weaned; 3-12 months) (Table 1). The infection rate of pre-weaned calves was $21.5 \% ; 10 \%$, $6 \%$ and $5 \%$ of them had C. parvum, C. bovis and C. ryanae, respectively. The infection rate of post-weaned calves was $29 \% ; 0 \%, 18 \%$ and $11 \%$ of the calves were infected with C. parvum, C. bovis and C. ryanae, respectively. Fragments of the small subunit (SSU) rRNA nucleotide sequences acquired in this study were deposited in the GenBank database under accession numbers; AB746195- AB746197. For C. parvum (AB746195), nucleotide sequences of the SSU rRNA gene derived from our fecal samples were identical to those of HQ009805 from dairy cattle from China. $C$. bovis (AB746197) was identical to JX515546 from dairy calves, China, and C. ryanae (AB746196) was identical to HQ179574 from dairy calves, China. Therefore, we conclude that $C$. parvum, $C$. bovis and $C$. ryanae detected here were not geographically unique. The sugar flotation method and microscopic examination were also performed for all 25 Cryptosporidium PCR-positive specimens. All C. bovis and C. ryanae PCR-positive specimens were negative by sugar flotation method. The C. parvum PCR-positive specimens were positive by sugar flotation method, except for only one specimen.

Correlation between diarrhea and detected genotype: We detected C. parvum, C. bovis and C. ryanae were detected in calves, however, only $C$. parvum was statistically correlated with diarrhea $(P<0.05)$ (Table 2). Among diarrheal Cryptosporidium positive samples, $C$. parvum was identified in 5 cases, but some calves with diarrhea were not infected C. parvum.

Relationship between Cryptosporidium infection and animal age: The percentages of each Cryptosporidium genotype represented among the 25 Cryptosporidium-positive specimens in the 2 age categories are presented in Table 1 . There were no significant correlations between Cryptosporidium infection and animal age. In post-weaned calves, the majority of infections were C. bovis and C. ryanae. C. bovis and $C$. ryanae were found in pre-weaned and post-weaned calves. The percentages of $C$. parvum, $C$. bovis and $C$. ryanae detected from pre-weaned calves were $47 \%, 29 \%$ and $24 \%$, respectively, whereas those from post-weaned calves were $0 \%, 63 \%$ and $38 \%$, respectively.

Subtyping of C. parvum by GP60 gene: Sequencing of GP60 gene PCR products was successful in all C. parvum isolates. DNA sequencing indicated that all GP60 nucleotide sequences were identical to each other and had a $100 \%$ similarity with $C$. parvum subtype IIaA15G2R1. GP60 nucleotide sequences acquired in this study were deposited in the GenBank database under accession numbers; AB746198.

\section{DISCUSSION}

Genotype analysis: Of the 107 fecal samples, 25 samples (23\%) were positive for Cryptosporidium infection based on 
PCR-sequence analyses. In Kenya, 20\% of dairy cattle were PCR-positive for Cryptosporidium [12]. In China, 18.82\% positive samples were identified from dairy cattle [3]. In India, $17.65-86.67 \%$ of calves were Cryptosporidium positive [29]. Again for calves, 25\%, 21.5\% and 10.7\% were Cryptosporidium positive in Romania, China and Brazil, respectively $[10,18,30]$. Therefore, our results were consistent with those epidemiologic data in the world. Furthermore, in this study, we collected 1-8 samples per farm. Those from more than half of farms were Cryptosporidium positive. Cryptosporidium positive farms were widely distributed in Ishikari District.

Here, Cryptosporidium species were detected; 8 (7\%), 10 $(9 \%)$ and 7 (7\%) samples had C. parvum, C. bovis and $C$. ryanae, respectively. In Hyogo Prefecture, 93\% of calves were reported to pass C. parvum oocysts [28]. Oocysts of this species have previously been isolated from cattle in many areas in Japan [1, 2, 13, 22, 33]. Here, the zoonotic species, C. parvum, was observed. Therefore, calves can be potential sources of cryptosporidial infections for humans and animals in Hokkaido.

C. bovis has been identified previously as Cryptosporidium genotype bovine B [7], and C. ryanae has been identified previously as the Cryptosporidium deer-like genotype [6]. These species have been detected all over the world [8]. It is very difficult to distinguish $C$. bovis and $C$. ryanae from $C$. parvum morphologically, and molecular analysis is needed for the differentiation of three intestinal Cryptosporidium spp. in cattle. For this reason, in Japan, these species have been described in only three studies. In Japan, C. ryanae was first detected from adult dairy cattle in Miyagi Prefecture [2], and C. bovis was first detected from pre-weaned calves with diarrhea in Hokkaido [13]. These studies showed only a single case infected with these species. Subsequently, 15 samples of $C$. bovis, 6 of $C$. ryanae and 2 of mixed infection were detected from post-weaned and adult beef cattle in Miyagi Prefecture [19]. This is the first description of $C$. ryanae in Hokkaido. Furthermore, this is first detection of $C$. ryanae from pre-weaned calves in Japan. All C. bovis and C. ryanae PCR-positive specimens were negative by sugar flotation method. Therefore, the low detection frequency of C. bovis and C. ryanae in Japan might have been the result of the wide use of microscopy in the previous studies. C. bovis and $C$. ryanae in younger calves might be concealed by an overwhelming $C$. parvum infection [8]. Using molecular diagnostic tools and examination of normal and calves with diarrhea, $C$. bovis and C. ryanae might be detected in other areas of Japan including Hokkaido.

C. andersoni is also a major species detected in cattle, especially post-weaned or adults [24]. There are several studies on C. andersoni detected in cattle in Japan [2, 11, 14, $16,17,20,26]$. Here, we did not detect this species, perhaps because we only sampled from calves.

Correlation between diarrhea and detected genotype: $C$. parvum, $C$. bovis and $C$. ryanae were detected along with the occurrence of diarrhea, but only $C$. parvum was statistically correlated with diarrhea $(P<0.05)$ (Table 2$)$. Not all diarrheal symptoms were caused by Cryptosporidium, but cattle with diarrhea are associated with $C$. parvum. There were some diarrhea samples that were $C$. bovis or $C$. ryanae positive. In a previous study, none of the calves infected with $C$. ryanae and $C$. bovis had any signs of disease [6, 7]. Therefore, there is a possibility that other pathogens or other environmental factors were related to diarrhea calves not infected C. parvum. However, our data are not sufficient to address this question. It is noteworthy that one calf which was $C$. parvum-positive by PCR did not have diarrhea and was negative by sugar flotation method. Although these results may come from recovering calves, these calves still discharge viable oocysts during their recovery. Therefore, asymptomatic infection of $C$. parvum is probably results in transmission to other calves.

Relationship between Cryptosporidium infection and animal age: In pre-weaned calves, $47 \%$ versus $29 \%$ and 24\% Cryptosporidium-positive calves were infected with $C$. parvum versus C. bovis and C. ryanae. In United States, $85 \%$ versus $9 \%$ and $5 \%$ of Cryptosporidium-positive dairy calves, which were 2 months of age and younger, were infected with $C$. parvum versus $C$. bovis and C. ryanae [25]. When the percentage of each species/genotypes of Cryptosporidium is represented, $C$. parvum constituted $97 \%$ of the species in pre-weaned calves [24]. Therefore, percentages of C. bovis and $C$. ryanae positive pre-weaned calves were higher than those of other countries. Our results are consistent with the report that $C$. parvum was most prevalent in pre-weaned calves [5].

Subtyping of C. parvum by GP60 gene: DNA sequencing showed that all $C$. parvum positive specimens had the $C$. parvum subtype IIaA15G2R1. This is the common subtype found in humans and cattle in many countries [24]. It is noteworthy that the obtained sequence was identical to that of $C$. parvum calf genotype reported from Kobe, Hokkaido and Gifu in Japan $[1,31]$.

ACKNOWLEDGMENTS. This study was supported by a JSPS Research Fellowship for Young Scientists, grant-inAids for Young Scientists, Exploratory Research, Scientific Research on Innovative Areas (3308) from the Ministry of Education, Culture, Science, Sports, and Technology (MEXT) of Japan, Bio-oriented Technology Research Advancement Institution (BRAIN), and Program to Disseminate Tenure Tracking System from Japan Science and Technology Agency (JST). We would like to thank the veterinarians of Ishikari NOSAI for collection of the specimens.

\section{REFERENCES}

1. Abe, N., Matsubayashi, M., Kimata, I. and Iseki, M. 2006. Subgenotype analysis of Cryptosporidium parvum isolates from humans and animals in Japan using the $60-\mathrm{kDa}$ glycoprotein gene sequences. Parasitol. Res. 99: 303-305. [Medline] [CrossRef]

2. Amer, S., Honma, H., Ikarashi, M., Oishi, R., Endo, M., Otawa, K. and Nakai, Y. 2009. The first detection of Cryptosporidium deer-like genotype in cattle in Japan. Parasitol. Res. 104: 745-752. [Medline] [CrossRef]

3. Chen, F. and Huang, K. 2012. Prevalence and molecular characterization of Cryptosporidium spp. in dairy cattle from farms in 
China. J. Vet. Sci. 13: 15-22. [Medline] [CrossRef]

4. de Graaf, D. C., Vanopdenbosch, E., Ortega-Mora, L. M., Abbassi, H. and Peeters, J. E. 1999. A review of the importance of cryptosporidiosis in farmanimals. Int. J. Parasitol. 29: 1269-1287. [Medline] [CrossRef]

5. Fayer, R., Santín, M. and Trout, J. M. 2007. Prevalence of Cryptosporidium species and genotypes in mature dairy cattle on farms in eastern United States compared with younger cattle from the same locations. Vet. Parasitol. 145: 260-266. [Medline] [CrossRef]

6. Fayer, R., Santín, M. and Trout, J. M. 2008. Cryptosporidium ryanae n. sp (Apicomplexa: Cryptosporidiidae) in cattle (Bos taurus). Vet. Parasitol. 156: 191-198. [Medline] [CrossRef]

7. Fayer, R., Santín, M. and Xiao, L. 2005. Cryptosporidium bovis n. sp (Apicomplexa: Cryptosporidiidae) in cattle (Bos taurus). $J$. Parasitol. 91: 624-629. [Medline] [CrossRef]

8. Feng, Y., Ortega, Y., He, G., Das, P., Xu, M., Zhang, X., Fayer, R., Gatei, W., Cama, V. and Xiao, L. 2007. Wide geographic distribution of Cryptosporidium bovis and the deer-like genotype in bovines. Vet. Parasitol. 144: 1-9. [Medline] [CrossRef]

9. Hall, T. A. 1999. BioEdit: a user-friendly biological sequence alignment editor and analysis program for Windows 95/98/NT. Nucleic Acids Symp. Ser. 41: 95-98.

10. Imre, K., Lobo, L. M., Matos, O., Popescu, C., Genchi, C. and Dărăbuş, G. 2011. Molecular characterisation of Cryptosporidium isolates from pre-weaned calves in Romania: is there an actual risk of zoonotic infections? Vet. Parasitol. 181: 321-324. [Medline]

11. Kaneta, Y. and Nakai, Y. 1998. Survey of Cryptosporidium oocysts from adult cattle in a slaughter house. J. Vet. Med. Sci. 60: 585-588. [Medline] [CrossRef]

12. Kang'ethe, E. K., Mulinge, E. K., Skilton, R. A., Njahira, M., Monda, J. G., Nyongesa, C., Mbae, C. K. and Kamwati, S. K. 2012. Cryptosporidium species detected in calves and cattle in Dagoretti, Nairobi, Kenya. Trop. Anim. Health. Prod. 44: S25S31. [Medline] [CrossRef]

13. Karanis, P., Eiji, T., Palomino, L., Boonrod, K., Plutzer, J., Ongerth, J. and Igarashi, I. 2010. First description of Cryptosporidium bovis in Japan and diagnosis and genotyping of Cryptosporidium spp. in diarrheic pre-weaned calves in Hokkaido. Vet. Parasitol. 169: 387-390. [Medline] [CrossRef]

14. Koyama, Y., Satoh, M., Maekawa, K., Hikosaka, K. and Nakai, Y. 2005. Isolation of Cryptosporidium andersoni Kawatabi type in a slaughterhouse in the northern island of Japan. Vet. Parasitol. 130: 323-326. [Medline] [CrossRef]

15. Larkin, M. A., Blackshields, G., Brown, N. P., Chenna, R., McGettigan, P. A., McWilliam, H., Valentin, F., Wallace, I. M., Wilm, A., Lopez, R., Thompson, J. D., Gibson, T. J. and Higgins, D. G. 2007. Clustal W and Clustal X version 2.0. Bioinformatics 23: 2947-2948. [Medline] [CrossRef]

16. Matsubayashi, M., Kimata, I., Abe, N., Tani, H. and Sasai, K. 2004. The detection of a novel type of Cryptosporidium andersoni oocyst in cattle in Japan. Parasitol. Res. 93: 504-506. [Medline] [CrossRef]

17. Matsubayashi, M., Nagano, S., Kita, T., Narushima, T., Kimata, I., Iseki, M., Hajiri, T., Tani, H., Sasai, K. and Baba, E. 2008. Genetical survey of novel type of Cryptosporidium andersoni in cattle in Japan. Vet. Parasitol. 158: 44-50. [Medline] [CrossRef]

18. Meireles, M. V., de Oliveira, F. P., Teixeira, W. F., Coelho, W. M. and Mendes, L. C. 2011. Molecular characterization of Cryptosporidium spp. in dairy calves from the state of São Paulo, Brazil. Parasitol. Res. 109: 949-951. [Medline] [CrossRef]
19. Murakoshi, F., Xiao, L., Matsubara, R., Sato, R., Kato, Y., Sasaki, T., Fukuda, Y., Tada, C. and Nakai, Y. 2012. Molecular characterization of Cryptosporidium spp. in grazing beef cattle in Japan. Vet. Parasitol. 187: 123-128. [Medline] [CrossRef]

20. Nagano, S., Matsubayashi, M., Kita, T., Narushima, T., Kirnata, I., Iseki, M., Hajiri, T., Tani, H., Sasai, K. and Baba, E. 2007. Detection of a mixed infection of a novel Cryptosporidium andersoni and its subgenotype in Japanese cattle. Vet. Parasitol. 149: 213-218. [Medline] [CrossRef]

21. Nichols, G. L., Chalmers, R. M., Sopwith, W., Regan, M., Hunter, C. A., Grenfell, P., Harrison, F. and Lane, C. 2006. p. 142. Cryptosporidiosis a Report on the Surveillance and Epidemiology of Cryptosporidium Infection in England and Wales. Drinking Water Directorate Contract Number DWI 70/2/201, Drinking Water Inspectorate, UK.

22. Sakai, H., Tsushima, Y., Nagasawa, H., Ducusin, R. J. T., Tanabe, S., Uzuka, Y. and Sarashina, T. 2003. Cryptosporidium infection of cattle in the Tokachi district, Hokkaido. J. Vet. Med. Sci. $\mathbf{6 5}$ : 125-127. [Medline] [CrossRef]

23. Santín, M. and Trout, J. M. 2008. Livestock. pp. 451-483. In: Cryptosporidium and Cryptosporidiosis (Fayer, R. and Xiao, L. eds.), CRC Press, Boca Raton, FL.

24. Santín, M., Trout, J. M. and Fayer, R. 2008. A longitudinal study of cryptosporidiosis in dairy cattle from birth to 2 years of age. Vet. Parasitol. 155: 15-23. [Medline] [CrossRef]

25. Santín, M., Trout, J. M., Xiao, L., Zhou, L., Greiner, E. and Fayer, R. 2004. Prevalence and age-related variation of Cryptosporidium species and genotypes in dairy calves. Vet. Parasitol. 122: 103-117. [Medline] [CrossRef]

26. Satoh, M., Hikosaka, K., Sasaki, T., Suyama, Y., Yanai, T., Ohta, M. and Nakai, Y. 2003. Characteristics of a novel type of bovine Cryptosporidium andersoni. Appl. Environ. Microbiol. 69: 691-692. [Medline] [CrossRef]

27. Thompson, H. P., Dooley, J. S. G., Kenny, J., McCoy, M., Lowery, C. J., Moore, J. E. and Xiao, L. 2007. Genotypes and subtypes of Cryptosporidium spp. in neonatal calves in Northern Ireland. Parasitol. Res. 100: 619-624. [Medline] [CrossRef]

28. Uga, S., Matsuo, J., Kono, E., Kimura, K., Inoue, M., Rai, S. K. and Ono, K. 2000. Prevalence of Cryptosporidium parvum infection and pattern of oocyst shedding in calves in Japan. Vet. Parasitol. 94: 27-32. [Medline] [CrossRef]

29. Venu, R., Latha, B. R., Basith, S. A., Raj, G. D., Sreekumar, C. and Raman, M. 2012. Molecular prevalence of Cryptosporidium spp. in dairy calves in Southern states of India. Vet. Parasitol. 188: 19-24. [Medline] [CrossRef]

30. Wang, R., Wang, H., Sun, Y., Zhang, L., Jian, F., Qi, M., Ning, C. and Xiao, L. 2011. Characteristics of Cryptosporidium Transmission in preweaned dairy cattle in Henan, China. J. Clin. Microbiol. 49: 1077-1082. [Medline] [CrossRef]

31. Wu, Z., Nagano, I., Boonmars, T., Nakada, T. and Takahashi, Y. 2003. Intraspecies polymorphism of Cryptosporidium parvum revealed by PCR-restriction fragment length polymorphism (RFLP) and RFLP-single-strand conformational polymorphism analyses. Appl. Environ. Microbiol. 69: 4720-4726. [Medline] [CrossRef]

32. Xiao, L. and Ryan, U. M. 2004. Cryptosporidiosis: an update in molecular epidemiology. Curr. Opin. Infect. Dis. 17: 483-490. [Medline] [CrossRef]

33. Yagita, K., Izumiyama, S., Tachibana, H., Masuda, G., Iseki, M., Furuya, K., Kameoka, Y., Kuroki, T., Itagaki, T. and Endo, T. 2001. Molecular characterization of Cryptosporidium isolates obtained from human and bovine infections in Japan. Parasitol. Res. 87: 950-955. [Medline] 